\title{
Direct Superior Ophthalmic Vein Access for Dural Arteriovenous Fistula Embolization
}

\author{
Myeong Ki Yeo ${ }^{1}$, Jiwook Ryu', Seok Keun $\mathrm{Choi}^{1}$, Eui Jong $\mathrm{Kim}^{2}$, Jong Min $\mathrm{Choi}^{1}$, Sung Ho Lee \\ Departments of ${ }^{1}$ Neurosurgery, ${ }^{2}$ Radiology, Kyung Hee University College of Medicine, Seoul, Republic of Korea
}

Corresponding author: Sung Ho Lee Department of Neurosurgery, Kyung Hee University College of Medicine, 26 Kyungheedae-ro, Dongdaemun-gu, Seoul 02447, Republic of Korea Tel: $+82-2-958-8385$

Fax: $+82-2-958-8380$

E-mail: nslsh@khu.ac.kr

Received: August 23, 2017

Revised: September 7, 2017

Accepted: September 8, 2017
Transvenous approach via inferior petrosal sinus is one of the most widely used route for endovascular treatment of dural arteriovenous fistula (dAVF) around cavernous sinus or carotid-cavernous fistula (CCF). When it is not possible, however, direct access through superior ophthalmic vein (SOV) could be considered alternatively. A 72-year-old female admitted to our hospital presented unilateral orbital pain, exophthalmos, and $6^{\text {th }}$ nerve palsy, which had been being aggravated during a month. Magnetic resonance imaging and conventional angiography revealed dAVF that originated from internal maxillary artery leaking into SOV. We attempted the conventional venous approach via femoral vein-external jugular vein and facial vein. However, we failed to proceed the microcatheter into the left SOV owing to its tortuous and stenotic point. We chose an alternative treatment strategy, surgical exposure of the SOV following linear incision on eyelid and direct cannulation. Two temporary clips (Yasargil mini curved) seized the SOV and FAST-Cath ${ }^{\mathrm{TM}}$ for children $(4 \mathrm{Fr}, 8.5 \mathrm{~cm}$ ) was inserted. We used a smaller sheath, which is shorter and softer than conventional endovascular catheter. It was beneficial in SOV puncture and catheter anchoring.

Key Words: Surgical exposure; Superior ophthalmic vein; Dural arteriovenous fistula; Embolization; Inferior petrosal sinus; Transvenous embolization

\section{INTRODUCTION}

Dural arteriovenous fistula (dAVF) indicates the abnormal connection between the artery and vein in the dura and is known to comprise of $10 \%$ to $15 \%$ of arteriovenous malformations ${ }^{5}$. The most common sites of dAVF are the transverse sinus and the cavernous sinus, which are common in the West and East respectively ${ }^{3,5)}$

The treatment of dAVF includes compressing the internal carotid artery, radiation therapy, surgical therapy, and endovascular therapy. Currently, endovascular therapy is the most preferred treatment modality due to its high success rate and safety, in which transvenous embolization is commonly being performed with the path via the internal jugular vein (IJV) and inferior petrosal sinus (IPS) being used most advantageously ${ }^{6,15,16)}$.

However, due to the failure of transvenous approach through femoral vein, the author would like to brief a case of dAVF embolization through superior ophthalmic vein (SOV).

\section{CASE REPORT}

A 72-year-old female admitted to our hospital presented with diplopia after falling down a month ago and exophthalmos which was aggravated 2 weeks ago. The patient was being treated for diabetes and Parkinson's disease and did not have any other specific disease history. During the time of admission, the patient showed visual blurring and diplopia with pain in the left eye in which a bruit could be auscultated. The patient's eye examination performed in the ophthalmology department showed restriction in lateral gaze, exophthalmos, and subconjunctival hemorrhage with visual acuity test showing 0.4 in the right eye and 0.3 in the left eye, and intraocular pressure of $17 \mathrm{mmHg}$ in the right eye and 25 in the left.

Brain magnetic resonance imaging performed after admitting to our department presented protrusion of the SOV and dAVF in the left cavernous sinus. Additionally, digital subtraction angiography (DSA) was performed using femoral artery in which a dAVF with blood supplied from the terminal of the maxillary artery and draining to the SOV and facial vein was observed (Fig. 1). Then, we planned the embolization 1 week later.

In order to treat the dAVF, embolization via the femoral vein, external jugular vein, and facial vein was attempted twice but the procedure failed as the microcatheter could not pass through the stenotic portion connecting the angular vein to the SOV (Fig. 2), therefore, due to the repeated failures, direct approach through the SOV was decided on. Embolization was 

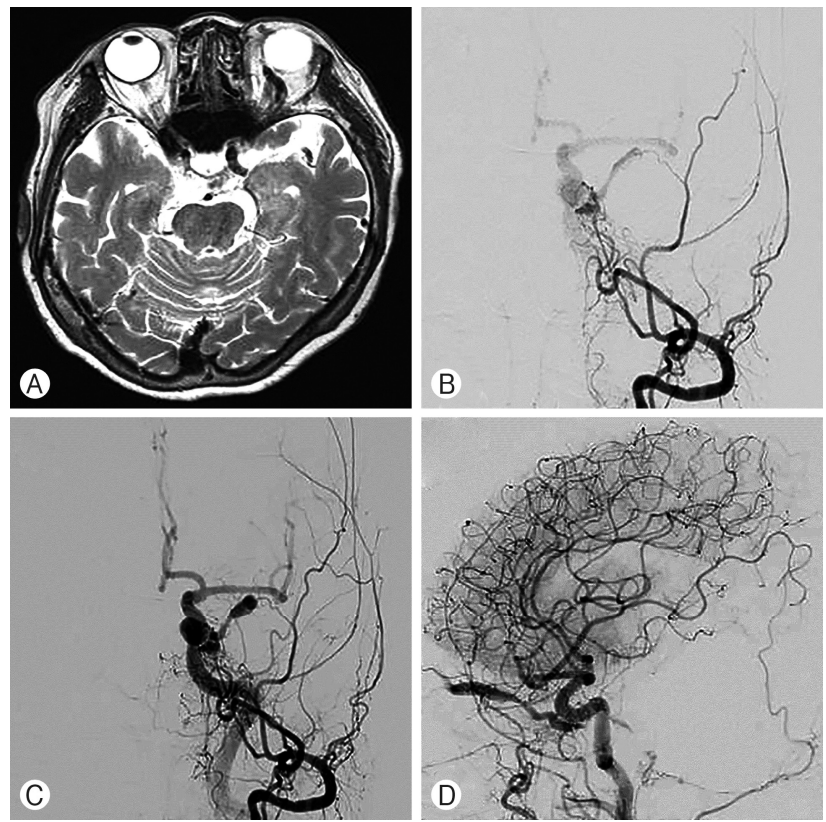

Fig. 1. (A) Left superior ophthalmic vein observed in the $T 2$ weighted image of brain magnetic resonance imaging. (B-D) Brain angiography showing dural arteriovenous fistula supplied by the left maxillary artery and draining to facial vein.
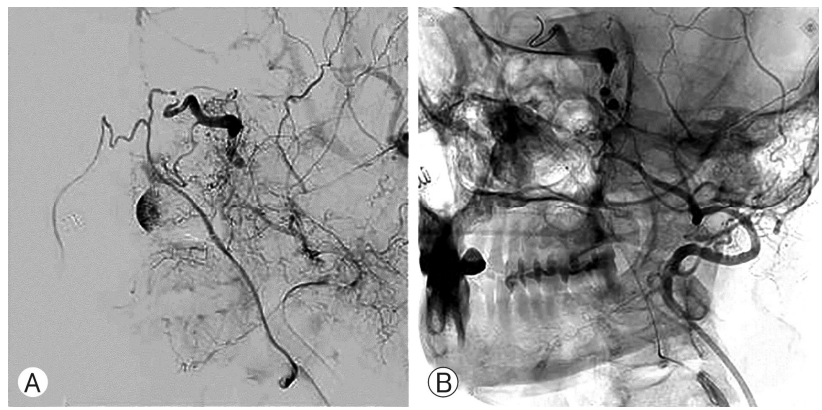

Fig. 2. (A) Approach to superior ophthalmic vein (SOV) via left facial vein attempted but stenosis observed at connection portion between angular vein and SOV. (B) Attempt through stenotic portion and passage of micro guidewire but failure of microcatheter entry.
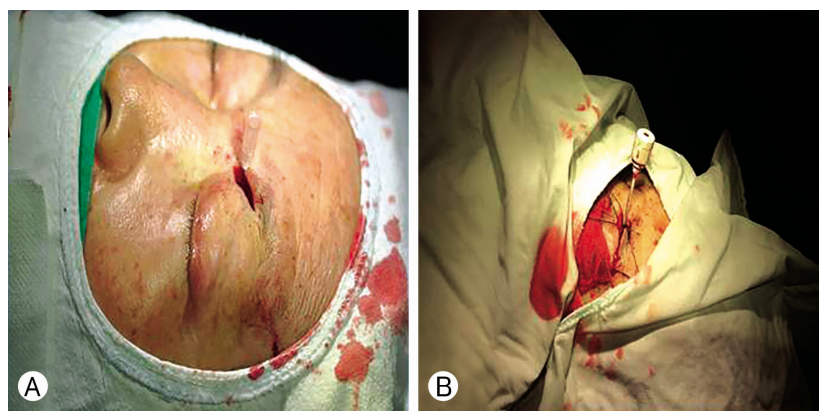

Fig. 3. (A) Location of superior ophthalmic vein (SOV by using needle during brain angiography. (B) Temporary clip (Yasargil mini curved clip) used in exposed SOV with insertion of pediatric FAST-Cath ${ }^{\mathrm{TM}}$ (4 Fr, $8.5 \mathrm{~cm}$; St. Jude Medical, Minnetonka, MN, USA).

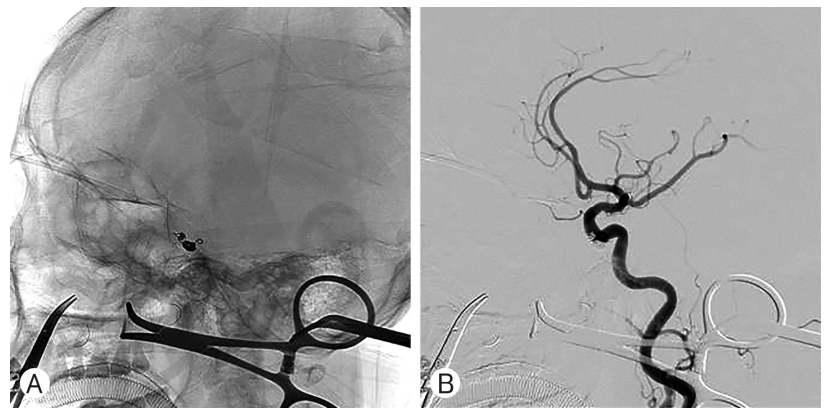

Fig. 4. Entry of microcathether to superior ophthalmic vein and embolization performed by using (A) pushable coils (Tornador ${ }^{\text {TM }} 3 \times 2$ $8 \mathrm{EA}$ ) and (B) detachable coils (axiom helix $2 \times 62$ EA, $2 \times 41$ EA), and obliteration of arteriovenous fistula confirmed.

performed after discussion on the exposure of the SOV with the ophthalmology and plastic surgery departments for the SOV approach.

After general anesthesia, the SOV was exposed through an incision in the left eyelid. Temporary clipping with Yasargil mini curved clip was done, pediatric FAST-Cath ${ }^{\mathrm{TM}}$ (4 FR, 8.5 cm; St. Jude Medical, Minnetonka, MN, USA) inserted (Fig. 3), and embolization performed by using pushable coils (TornadoR; Cook Inc., Bloomington, IN, USA; $3 \times 28$ EA) and detachable coils (Axium ${ }^{\mathrm{TM}}$ Helix, Irvine, CA, USA; $2 \times 62 \mathrm{EA}, 2 \times 41 \mathrm{EA}$ ) (Fig. 4). The patient was discharged without any particular neurologic symptoms and outpatient follow-up after 2 weeks showed normalized intraocular pressure and improvement of exophthalmos.

\section{DISCUSSION}

The dAVF is the abnormal vascular connection between the artery and vein arising from the dura, and is known to be common among the elderly, postmenopausal women with a history of hypertension, and secondary causes from trauma or surgery ${ }^{11)}$. Characteristic symptoms include diplopia or ocular symptoms such as exophthalmos or ptosis which are common, and other symptoms such as headache or intracranial bruit".

Treatment modalities for dAVF includes blocking the blood flow by clot formation in the cavernous sinus by compressing the ipsilateral internal jugular artery, surgical treatment, and endovascular treatment, in which the current method of preference is the endovascular treatment ${ }^{15,16)}$.

The endovascular treatment method could be classified according to the method of approach into the transarterial approach and the transvenous approach. The transarterial approach is known to be difficult for complete embolization as there are many dural arteries and small branches, and has a high recurrence rate ${ }^{7}$. In comparison, the transvenous approach via the IJV and IPS through the femoral vein is most commonly used with the advantage of a high success rate in treatment compared to other modalities ${ }^{5,6)}$. 
Table 1. Previous patient case report of arteriovenous fistula using transvenous approach

\begin{tabular}{|c|c|c|c|c|c|c|c|}
\hline Studies & Age/Sex & Diagnosis & Approach & Microcatheter & Material & Occlusion & Anchoring \\
\hline Ha et al., 201 1 & $69 / F$ & DAVF & SOV & $\begin{array}{l}\text { Microcatheter (Prowler 18; Cordis, } \\
\text { Miami Lakes, FL, USA) }\end{array}$ & Coil & Complete & \\
\hline $\begin{array}{l}\text { Chalouhi et al., } \\
2012^{2)}\end{array}$ & $60 / F$ & CCF & SOV & $\begin{array}{l}\text { Echelon-10 microcatheter } \\
\text { (ev3 Endovascular, Plymouth, MN, } \\
\text { USA) }\end{array}$ & Onyx 18 & Complete & \\
\hline $\begin{array}{l}\text { Tanaka et al., } \\
2014^{13)}\end{array}$ & $37 / F$ & CCF & SOV & $\begin{array}{l}\text { Excelsior } 45^{\circ} \text { (Boston Scientific, } \\
\text { Natick, MA, USA) }\end{array}$ & Coil & Incomplete & \\
\hline $\begin{array}{l}\text { Thiex et al., } \\
2014^{14)}\end{array}$ & $66 / F$ & CCF & FV & 4 Fr short access sheath (Cordis) & Coil & Complete & \\
\hline $\begin{array}{l}\text { Alexandre et al., } \\
2017^{1)}\end{array}$ & $62 / M$ & DAVF & $\mathrm{FV}$ & $\begin{array}{l}\text { Echelon-10 microcatheter } \\
\text { (ev3 Endovascular) }\end{array}$ & Coil & Complete & \\
\hline This study, 2017 & $71 / F$ & DAVF & SOV & $\begin{array}{l}\text { FAST-Cath }{ }^{\mathrm{TM}}(4 \mathrm{Fr}, 8.5 \mathrm{~cm} \text {; St. Jude } \\
\text { Medical, Minnetonka, MN, USA) }\end{array}$ & Coil & Complete & $\begin{array}{l}\text { Temporary clip } \\
\text { (Yasargil mini } \\
\text { curved clip) }\end{array}$ \\
\hline
\end{tabular}

F: female; M: male; dAVF: dural arteriovenous fistula; CCF: carotid-cavernous fistula; SOV: superior ophthalmic vein; FV: facial vein; Fr: French.

If access to the IPS in the transvenous approach is unavailable, another approach through the pterygoid plexus, angular vein, and facial vein exists but there is a difficulty in treatment due to vessel curvature or hypoplasia, and stenosis ${ }^{8)}$.

However, the approach through the SOV has a high success rate compared to other approaches and a low rate of complications, therefore being considered an alternative approach to the access via IPS through the femoral vein. The nonexistence of valves and the straightness of the vessel pathway are also advantages of the endovascular procedure using the $\mathrm{SOV}^{12)}$.

Various case reports of endovascular embolizations through the SOV have been reported (Table 1). Reis et al. ${ }^{12)}$ have performed endovascular embolization through the SOV on 85 patients based on previous study materials and stated that 76 among the 85 patients showed complete occlusion (of the malformation) which reached treatment success rate up to $95 \%$. White et al. ${ }^{15)}$ have reported on 8 patients in which the SOV approach was used for endovascular embolization as the transfemoral approach was not possible. Goldberg et al. ${ }^{4)}$ have reported a case in which successful dAVF occlusion with improvement of eye sight and reduction of intraocular pressure were achieved, though the study also stated limitations of the unfeasibility of endovascular treatment procedure through the SOV if the vein is located deep within the orbit or not dilated.

Incision methods in the SOV approach consists of using the upper lid fold or incising under the eyebrow. There are studies suggesting that making an incision close to the superior orbit is favorable, and in our case, we determined the location of the SOV through angiography and performed skin incision by using the upper lid fold, which was the shortest route of access to the vein ${ }^{9,12)}$. In the SOV approach, various complications such as hematoma or infection at the procedure site or the orbit, ophthalmic artery occlusion, and oculomotor palsy may occur, thus, a trained physician with an understanding of the accurate anatomical structures of the orbital area would be considered necessary ${ }^{7,10)}$.

\section{CONCLUSION}

In cases of dAVF treatment where endovascular procedures through conventional routes are not feasible, endovascular procedure through the SOV should be considered, and in order to increase success rates and reduce complications, the exact location and exposure of the SOV through angiography should be performed as well as using a catheter with a narrow diameter and temporary clip which could be valuable for the procedure such as in our case.

\section{CONFLICTS OF INTEREST}

No potential conflict of interest relevant to this article was reported.

\section{REFERENCES}

1. Alexandre AM, Visconti E, Lozupone E, D'Argento F, Pedicelli A: Embolization of dural arteriovenous fistula of the cavernous sinus through percutaneous ultrasound-guided puncture of the facial vein. World Neurosurg 99:812 e813-812 e820, 2017

2. Chalouhi N, Dumont AS, Tjoumakaris S, Gonzalez LF, Bilyk JR, Randazzo C, et al.: The superior ophthalmic vein approach for the treatment of carotid-cavernous fistulas: A novel technique using onyx. Neurosurg Focus 32:E13, 2012

3. Cheng KM, Chan CM, Cheung YL: Transvenous embolisation 
of dural carotid-cavernous fistulas by multiple venous routes: a series of 27 cases. Acta Neurochir (Wien) 145:17-29, 2003

4. Goldberg RA, Goldey SH, Duckwiler G, Vinuela F: Management of cavernous sinus-dural fistulas. Indications and techniques for primary embolization via the superior ophthalmic vein. Arch Ophthalmol 114:707-714, 1996

5. Ha JG, Jeong HW, In HS, Choi SJ: Transvenous embolization of cavernous sinus dural arteriovenous fistula using the direct superior ophthalmic vein approach: a case report. Neurointervention 6:100-103, 2011

6. Kim MJ, Shin YS, Ihn YK, Kim BM, Yoon PH, Oh SY, et al.: Transvenous Embolization of Cavernous and Paracavernous Dural Arteriovenous Fistula through the Facial Vein: Report of 12 Cases. Neurointervention 8:15-22, 2013

7. Lee JW, Kim DJ, Jung JY, Kim SH, Huh SK, Suh SH, et al.: Embolisation of indirect carotid-cavernous sinus dural arteriovenous fistulae using the direct superior ophthalmic vein approach. Acta Neurochir (Wien) 150:557-561, 2008

8. Lim NC, Lin HA, Ong CK, Sundar G: Treatment of dural carotid-cavernous fistulas via the medial ophthalmic vein. Orbit 34: 345-350, 2015

9. Miller NR, Monsein LH, Debrun GM, Tamargo RJ, Nauta HJ: Treatment of carotid-cavernous sinus fistulas using a superior ophthalmic vein approach. J Neurosurg 83:838-842, 1995

10. Oishi H, Arai H, Sato K, lizuka Y: Complications associated with transvenous embolisation of cavernous dural arteriovenous fistula. Acta Neurochir (Wien) 141:1265-1271, 1999

11. Quinones D, Duckwiler G, Gobin PY, Goldberg RA, Viñuela F: Embolization of dural cavernous fistulas via superior ophthalmic vein approach. AJNR Am J Neuroradiol 18:921-928, 1997

12. Reis CV, Gonzalez FL, Zabramski JM, Hassan A, Deshmukh P, Albuquerque FC, et al.: Anatomy of the superior ophthalmic vein approach for direct endovascular access to vascular lesions of the orbit and cavernous sinus. Neurosurgery 64:318-323; discussion 323, 2009

13. Tanaka T, Hayakawa M, Sadato A, Adachi K, Watabe T, Maeda $\mathrm{S}$, et al.: Transvenous embolization for carotid-cavernous fistula in a patient with vascular type of ehlers-danlos syndrome--direct superior ophthalmic vein approach: Case report. Neurol Med Chir (Tokyo) 54:155-160, 2014

14. Thiex R, Gross BA, Gupta R, Wyers MC, Frerichs KU, Thomas AJ: Transvenous approach to carotid-cavernous fistula via facial vein cut down. J Clin Neurosci 21:1238-1240, 2014

15. White JB, Layton KF, Evans AJ, Tong FC, Jensen ME, Kallmes DF, et al.: Transorbital puncture for the treatment of cavernous sinus dural arteriovenous fistulas. AJNR Am J Neuroradiol 28: 1415-1417, 2007

16. Yu SC, Cheng HK, Wong GK, Chan CM, Cheung JY, Poon WS: Transvenous embolization of dural carotid-cavernous fistulae with transfacial catheterization through the superior ophthalmic vein. Neurosurgery 60:1032-1037; discussion 1037-1038, 2007 